governors, his Majesty expressed his belief that the public would not allow this beneficent undertaking to be hindered by the want of the necessary funds.

"This block will cost upwards of $£ 100,000$.

"In view of the misapprehension as to the policy and plans of the governors, which appears to prevail in certain quarters, it may be well to state that such repairs as have been carried out in the existing buildings this year have been of a strictly limited character, the principal outlay being less than $£ 1,000$ for the electric lighting of the west wing of the hospital, the necessity of which was admitted on all hands.

"The governors are fully alive to the importance of ultimately achieving a complete reconstruction of the hospital buildings. In particular they are anxious to provide, as soon as possible, a pathological department, new mortuary, and post-mortem rooms, and a nurses' home. The accommodation for the nurses, as at present existing, is of a makeshift character, and they are housed, for the most part, in old and inadequate buildings.

"It must not be supposed that the governors kave in any way dfparted from the intention they have repeatedly expressed of reconstructing the hospital in its entireiy in accordance with the views of their medical staff. But this can only be done prudently as funds come in.

"The critics of St. Bartholomew's have overlooked the fact that the committee, appointed by the late Lord Mayor to consider the question, resolved, by 15 to one, that it was essential, in the interests of the public, that the hospital should be rebuilt on the site which it had occupied for close on 800 years.

"The governors feel that, in carrying out the policy adopted by the almost unanimous verdict of what was in great measure an independent body, they have the right to appeal for help to the charitable public and especially to those who are indebted to their connection with the City for prosperity and wealth.

"The history of St. Bartholomew's, and the work it has done during many hundreds of years, are too well known to need recapitulation here; but I would beg leave to impress upon sour readers the urgency of helping this ancient institution to adapt itself to the circumstances and needs of the present day, without impairing its completeness and efficiency by largely diminishing its income."

"It is but right to remind those who, in the interests of other institutions, blame the governors for not postponing their appeal that a single year's postponement means a sacrifice of $£ 9,000$ interest and sinking fund on the cost of the land bought from Christ's Hospital."

St. Bartholmew's Hospital, October 25t'.

The Westminster Gazette of the 27th ult. publishes the following interview :-

\section{THE FUTURE OF "BART"S."}

"A Westminster representative had a conversation yesterday with Mr. Andrew Motion, who is a governor of the hospital and a member of the House Committee. That gentleman had only just heard of Sir Henry Burdett's suggestion that he should become the head of affairs at Bart's.

“' I would do anything to see St. Bartholomew's placed upon a sound footing,' said Mr. Motion. 'I live 100 miles from London, but I would gladly give up a year of my life if I could ds any good. I agree that a stringent administrative reform is absolutely necessary. A' present it is little less than a farce my attending meetings of the House Committee. It is difficult to obtain any infurmation as to what is being done. Last week I attended a meeting at which it was proposed to grant the retiring secretary, Mr. Cross, a pension of $£ 900$ a year. I, without in any way questioning the possibility that $\mathrm{Mr}$. Cross might, for his services, deserve this large pension, asked for particulars to show how the amount was arrived at. I got no particulars, nor was my request backed up by any other member. I hear now that the pension has been granted. It does, indeed, seem a large amount to grant, when the hospital is appealing in vain to the pablic for funds.

" ' Our income is about $£ 90,000$ a year, but before that is free to be applied to the practical purposes of the hospital it has been diminished in one way and another by $£ 30,000$. It seems ridiculous, and I think nothing will meet the present muddle but a properly organised commission of inquiry, or a royal commission, if necessary.'"

\section{EDITOR'S LETTER-BOX.}

\section{EAST LONDON MEDICAL : ETY AND HOSPITAL ABUSE.}

To the Editor of THE HOSPITAL.

DEAR SIR,-Since the appearance in the public press of the report of the quarterly meeting of the Governors of the London Hospital many comments have been made on it, and allusion has been frequently made to the East London Medical Society; so much so that the Society feels that it is necessary to clearly define its position, in order that there may be no misunderstanding in the mind of the public as to the object it is striving for.

Last May a deputation of the East London Medical Society waited on the Board of Management of the London Hospital to ask for a reform of various abuses in the management of the hospital. The abuses complained of fell under two main heads:-(1) The part payment system under which patients are expected to pay a proportion of the cost of the medicines and dressings supplied to them; and (2) insufficient scrutiny, whereby patients, who are well able to pay for treatment privately, are enabled to take advantage of a public charitable institution.

The existence of abuses was admitted by the hospital authorities and it was shown that in one important branch, the casualty department or receiving-room, the scrutiny was not merely imperfect but practically non-existent; for the addresses of patients were not asked, all comers being treated without question as to their means. The steps proposed by the hospital for the abatement of the evil have now appeared in the press, and it is principally on them that the East London Medical Society wishes to express its views.

1. "Large notices have been placed in the outpatients" department stating that a small charge is made for medicines and dressings, but no charge for advice." The part payment system, which is thus affirmed, is objected to by medical practitioners, because they find that it induces many patients who are too well off to deserve hospital relief to go to hospitals for treatment in the belief that they are paying for all they receive, and so are not receiving charity; and it also acts as a salve to the consciences of others who go to hospitals knowing that they have really no right to hospital relief. The Society holds that notices should be placed in all departments of the hospital and on the cards issued to patients that the institution is for charitable relief only.

2. "The addresses of all patients will be taken, and the books open to the inspection of any local practitioner who cares to inspect them." The registration of addresses is so obviously necessary in any inquiry as to the means of the patients, that it is amazing that it should ever have been neglected; but the inspection of the books by local practitioners is a part of that system of espionage to which the Society strongly objects.

3. "Local practitioners are invited to visit the out? 
patients' department, and on recognising any patient known as being unsuitable for hospital treatment, asked to communicate with the secretary." This suggestion, which invites medical men to act as detectives, was made to the deputation of the Society at the hospital, and was rejected as quite impossible. The hospital would have shown better taste had it let the suggestion drop, instead of repeating it and allowing it to go to the press.

4. "The Jewish Board of Guardians have been approached, and consented to help the hospital in making inquiries with regard to Jewish patients." The intimate acquaintance of the Jewish Board of Guardians with the Jewish poor should be a great help in eliminating unsuitable cases.

5. "The Metropolitan Provident Dispensary, which has a branch opposite the hospital, has agreed to take over any patients sent from the hospital at a reduced charge." The Society has been informed that the dispensary intends to institute a further inquiry to ascertain whether the patients are poor enough to deserve dispensary treatment. Without this the hospital plan would be most futile, for large numbers of patients now treated at the hospital are well able to pay the fees of a private practitioner, and consequently have no right to go to either the dispensary or the hospital. It is not easy to see why most of the unfit cases should not be referred direct to private practitioners, for the difference between payment for medicine and dressings at the hospital and reduced payments at the dispensary cannot be very great.

6. "The committee is in communication with the Oharity Organisation Scciety, and it is hoped that this scciety will be able to advise the hospitals as to the best means for inquiring about patients, while the hospital is willing to pay $£ 100$ per annum to the society for an almoner to be stationed in the receiving rooms." This should lead to an improvement in the inquiry system and so to more efficient detection of offenders.

7. "The secretary has made arrangements to visit every patient admitted on the day after arrival, and if found the patient should not receive hospital treatment, he or she is to be discharged and asked to give a donation for the time he or she remains in the bospital." This is not an entirely practicable suggestion. In a hospital where the admissions are so numerous (sometimes, it is said, as many as 60 in a day) it is not possible for a busy man like the secretary to inquire into the circumstances of them all. By all means let any urgent case be admitted at once without inquiry, but whenever there is no urgency the admission order ought not to be given until an inquiry has shown that the case is one suitable for hospital relief. The society greatly regrets that no rule has been made that all patients whose means are sufficient to enable them to pay the fees of a private practitioner shall be refused any attendance beyond first aid. In this way a considerable economy of the hospital funds might 'se effected.

In conclusion the Society, while recognising the extreme difficulty of preventing abuse, wishes to point out (1) That at present advantage is taken of the lax inquiry system by a very large number of persons who ought not to receive charitable relief, and who in many instances are really wealthy; (2) That the funds supplied by the charitable are thus misappropriated, the persons for whom they are intended being often deprived of relief in consequence; (3) That the medical profession is subjected to a most unfair competition with subsidised institutions; (4) That the indiscriminate administration of relief tends to pauperise many of the recipients and to lessen habits of thrift; (5) That with more efficient means of preventing abuse the poverty of hospitals would be diminished, perhaps even abolished; and (6) That the hospital authorities must not forget in delegating their duties of scrutiny, that they are primarily responsible to the charitable public for the proper expenditure of the monies subscribed.

Yours faithfully,

F. HARRIS WhITE,

Hon. Secretary, East London Medical Society.

\section{Medical Appointments.}

J. H. Montgomerie Bell, M.B., Ch.B., Non-resident House Surgeon to Dr. R. W. Philip at the Edinburgh Royal Infirmary. Edward Mansfield Brockbank, M.D., M.R.C.P., Junior Honorary Physician, Manchester Children's Hospital. R. G. Brown, M.B., B.S.Aberd., Resident Assistant Medical Officer, Lambeth Parish Infirmary. Harold R. Cross, L.S.A., Assistant Medical Officer, Storthes Hall Asylum, Kirkburton, near Huddersfield. D. Livingstone Davies, M.R.C.S., L.R.C.P.Lond., Medical Officer to the Post Offices of Criccieth, Chwilog, Garu Dolheumaeu, and Llangybi. W. B. Felton, L.R.C.P. and S.Irel., District Medical Officer, St. Columb Major Union. James Haig Ferguson, M.D., F.R.C.P.Edin., Assistant Accoucheur to Professor A. R. Simpson at the Edinburgh Royal Maternity and Simpson Memorial Hospital. W. Ernest Jones, M.R.C.S., L.R.C.P., Inspector-General of Asylums for the Insane in Victoria, Australia. N. Kalomiris, L.R.C.P., M.R.C.S., F.R.C.S., Clinical Assistant to the Chelsea Hospital for Women. Harold Kerr, M.B., Ch.B.Edin., Resident Medical Officer to the Florence Nightingale Hospital for Infectious Diseases, Bury, Lancs. M. E. Leicester, L.R.C.P. and S.Edin., L.F.P.S.Glasg., District Medical Officer of the Liskeard Union. James Lockhead, M.B., Ch.B, House Surgeon, Edinburgh Royal Maternity and Simpson Memorial Hospital. Alexander Paine, M.D., B.S.Lond., D.P.H.. Joint Pathologist with Dr. D. J. Morgan to the Cancer Hospital, Fulham Road. Walter Brock Parsons, Assistant Anæsthetist to the Royal Dental Hospital, Leicester Square. H. W. Pigeon, M.D., Resident Medical Officer at the Chatham Islands, New Zealand. A. E. Pinniger, L.R.C.P., M.R.C.S., Resident Assistant Medical Officer, Islington Parish Infirmary. J. A. Ross, M.A., M.B., Ch.B.Edin., Junior House Surgeon at the Croydon Hospital. D. Spence, M.B., Assistant Medical Officer, South Shields Union Workhouse. A. C. Strain, M.B., Ch.B., House Surgeon, Edinburgh Royal Maternity and Simpson Memorial Hospital. $R$. Cecil D. Wall, M.D.Oxon., Assistant Physician to the London Hospital. J. A. Webster, M.D., Honorary Medical Officer, Launceston Hospital, Tasmania. W. Cheyne Wilson, M.D.Edin., Senior Phrsician to the Plymouth Public Dispensary.

\section{"Tho E0spital" Institutional Ibrary.}

"Hospitals and Asylums of the World" \& Vols., with a Port. Polio of Plans, complete $£ 12$ 12s.

"Burdett's Hospitals and Charities, 1904." 5s. net.

“Burdett's Official Nursing Directory." 8s. net.

"Cottage Hospitals, General, Fever, and Convalescent." 10s. 6d,

"Uniform System of Accounts for Hospitals and Public Instita. tions." New Edition, 1s. net.

"Hospital Expenditure: The Commissariat." 2s.6d.

"A Legal Handbook for the Use of Hospital Authorities." 28. $6 \mathrm{~d}$.

"The Cottage Hospital Case Book or Register of Patienta." 10w. and 12s. $6 \mathrm{~d}$.

All these are published by the Scirrstrifo Priss, Ltd., and may be obtained through any bookseller, or direct from the publishere, 28 and 29 Southampton Street, Strand, London, W.C.

\section{Medical Appointments.}

A $\mathrm{N}$ EXAMINATION OF CANDIDATES for entry into A the Medical Department of the Royal Nary will be held on 14th November next and following days at Examination Hall, Thames 14th November

The forms to be filled up by Candidates will be supplied on application to the MEDICAL DIRECTOR-GENERAL.

30th September, 1904.

Admiralty,

18 Victoria Street, S.W. 